\title{
Communication
}

Journal of Photopolymer Science and Technology

Volume 2, Number 2(1989) $143-146$

\section{Photochromic Properties of Water-Soluble Spiropyrans in Reversed Micelles}

\author{
Hideo Tomioka*, Shigeru Murata and Fumihiro Inagaki \\ Department of Industrial Chemistry, Faculty of Engineering \\ Mie University, Tsu, Mie 514
}

Since the first studies on the photochromism of spiropyrans $\left(1^{\prime}, 3^{\prime}, 3^{\prime}-\right.$ trimethylspiro[2H-1-benzopyran-2,2'-indoline](SP) by Fischer et al in 1952 [1], a great number of studies have been done on their properties [2]. This is mainly because of their potential usefulness as a photpresponsive material owing to the intense color of merocyanine dyes (MC) reversibly developed upon irradiation. Photochromic properties of SP are known to be greatly influenced by the nature of the surrounding matrices presumably due to a large steric requirement during the isomerization as well as a great sensitivity of the colored form to the polarity of the media. In this connection, the photochromic behaviours of SP in solution [2], polymer films [3], monolayer [4] and bilayer membrane [5], Langmuir-Blodgett multilayers [6], 1iquid crystals [7], and micelles [8] have been extensively studied. The effect of solvents on the photochromism of SP have been extensively studied in organic solvents. Both the wavelength $(\nu)$ of the absorption maximam of $M C$ and the rate constant $(\mathrm{k})$ of ring closure change clearly as the solvent polarity is varied and usually the excellent linear correlation of $\ln k$ vs $v$ exists [5]. In a heterogenous media, however, a marked deviation from the linearity has been often observed presumably due to the local order, viscosity as well as the sites of solubilization. It is quite important, then, to know the exact factors which control the photochromic properties in these heterogenous media. Thus, we prepared the water-soluble SP (1) bearing ammonium ion hydrophilic heads and examined the rate constants of the isomerization in the anionic and cationic reversed micelles. In addition, in order to know the exact factors controlling the reaction rates in the water pool of reversed micelles, we measured the absorption maximum for MC in the micelles and compared them with solvents of known polarity.

As has been observed with several spiropyrans bearing hydroxy, carboxy, amino [9], or sulfoxy groups [8] on either ring, the present compound was 


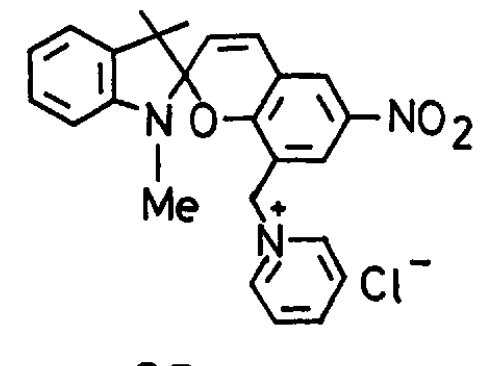

$S P-1$

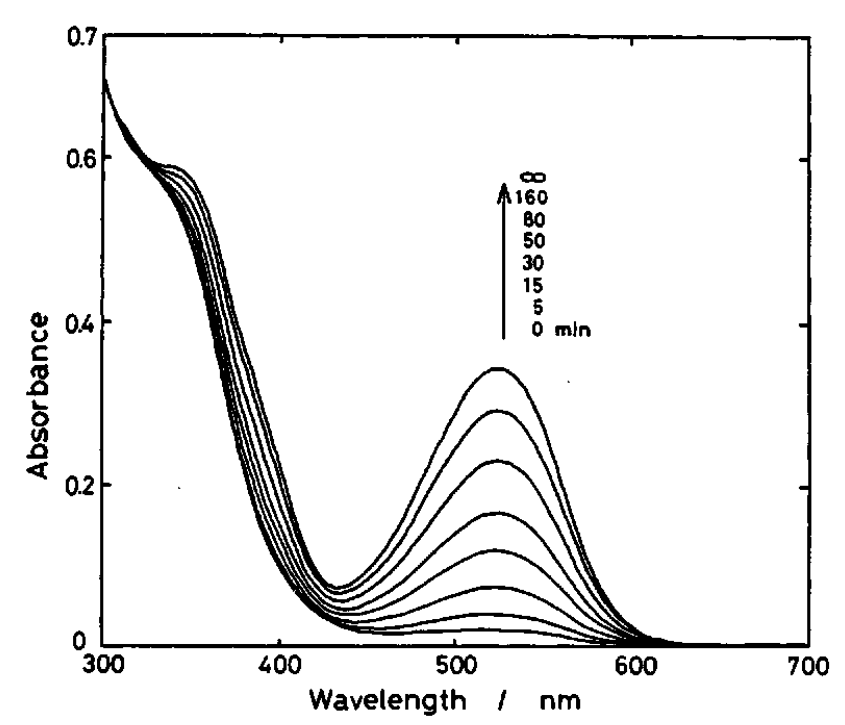

Figure 1. Visible spectral change for the thermocoloration of SP-1 in the dark in the $\mathrm{DDAC} / \mathrm{H}_{2} \mathrm{O} / \mathrm{PhH}$ reversed micelles at $37.0^{\circ} \mathrm{C}$.

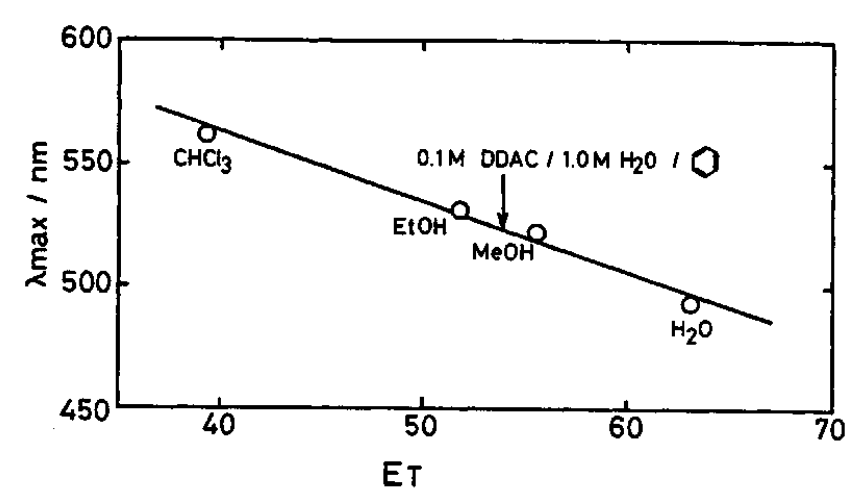

Figure 2. Absorption maxima of $M C-1$ as a function of $\mathrm{E}_{\mathrm{T}}$ at $37.0^{\circ} \mathrm{C}$. Arrow shows the absorption maximum in the $\mathrm{DDAC} / \mathrm{H}_{2} \mathrm{O} / \mathrm{PhH}$
reversed micelles.

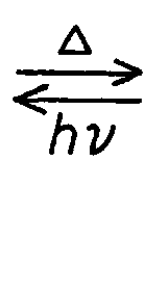

found to show reverse photochromism in polar solvent. Thus, SP-1 shows purple color due to $M C-1$ upon solving in polar solvents and the color of the solution fades upon irradiation of the visible light corresponding to the absorption maximum. The resulting colorless solution turns purple again when it was kept in the dark (Figure 1). The absorption maximum shows a blue shift with an increase in the polarity of the solvents employed. This is interpreted as indicating that the dipolar ground state is more stabilized than the excited state as the polarity of the solvent increases. A plot of the $\lambda \max$ of MC-1 against the wellestablished standard polarity parameter, $E_{T}$, is shown in Figure 2. A good correlation between $\lambda \mathrm{max}$ and $\mathrm{E}_{\mathrm{T}}$ was obtained substantiating the validity of 1 as a polarity probe.

The thermal isomerization of MC-1 to SP-1 exhibited simple first order kinetics. The firstorder rate constants (k) for the thermocoloration of SP-1 under various conditions are summarized in Table 1. In a homogeneous 
Table 1. Photochromic Properties of 1 under Various Environments at $37.0^{\circ} \mathrm{C}$.

\begin{tabular}{lccc}
\hline Environment & $\begin{array}{r}\lambda \max (\mathrm{nm}) \\
\text { of } \mathrm{MC}-1\end{array}$ & $\begin{array}{c}\text { rate } \times 10^{5} \\
\left(\mathrm{~s}^{-1}\right)\end{array}$ & $\begin{array}{c}\text { relative rate } \\
\text { ratio }\end{array}$ \\
\hline $\mathrm{H}_{2} \mathrm{O}$ & 493 & 1.56 & 1.00 \\
$\mathrm{MeOH}$ & 522 & 4.56 & 2.92 \\
EtOH & 531 & 5.90 & 3.78 \\
$0.1 \mathrm{M} \mathrm{DDAC/1.0M} \mathrm{H}_{2} \mathrm{O} / \mathrm{PhH}$ & 525 & 37.4 & 24.0 \\
\hline
\end{tabular}

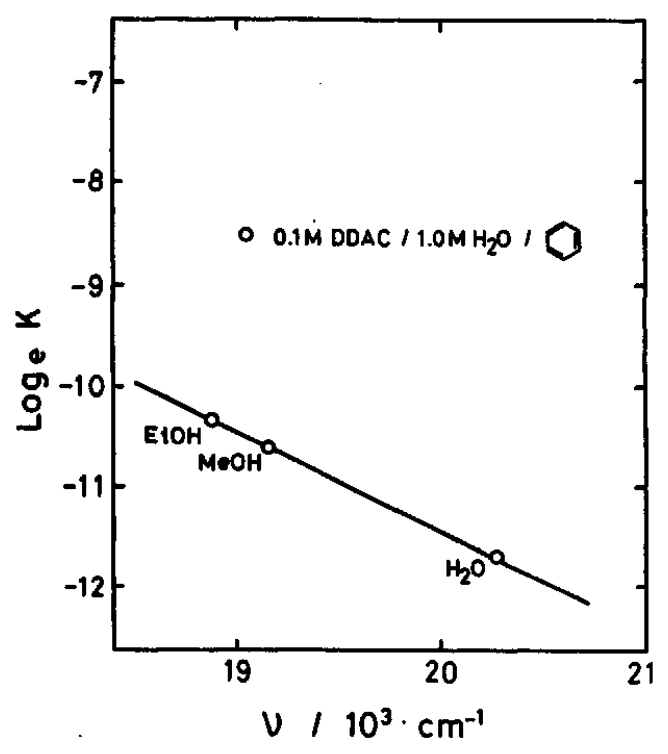

Figure 3. Plot of In $k$ against the absorption maxima of $M C-1$ in various media as indicated. system, the rate of thermocoloration decreases with a increase in solvent polarity. This is due to polarization inductive solute/solvent interactions. A plot of $\ln k$ against the energy ( $v$ ) of visible electronic absorption transition of MC-1 showed that the excellent linear correlation exists between lnk and (Figure 3 ).

SP-1 homogenized in $0.1 \mathrm{M}$ didodecyldimethylammonium chloride (DDAC)/ $1.0 \mathrm{M}$ $\mathrm{H}_{2} \mathrm{O} /$ benzene reversed micelles also shows reverse photochromism. The absorption maximum of MC-2 in the DDAC micelles was $525 \mathrm{~nm}$, close to that in methanol (Figure 2), which suggests the polarity of the microenvironment around $M C-1$ in the DDAC reversed micelles is considered to correspond to that of methanol. The kinetics of isomerization $\mathrm{SP}-1 \rightarrow \mathrm{MC}-1$ in the DDAC reversed micelles are analogous to those in polar solvents like methanol where simple first-order kinetics were observed. The first-order rate constant for the conversion rate from $\mathrm{MC}-1$ to SP-1 in the DDAC reversed micelles was accelerated by about 8 times compared with that in methanol, although the microscopic polarity of the micelles is comparable to that in methanol as described above. The observed acceleration must be explained, then, in terms of an effect other than the solvent polarity of the microenvironment.

It should be noted here, however, that the isomerization rate in a heterogeneous media is generally decelerated. For example, the thermocoloration rates of $1^{\prime}, 3^{\prime}, 3^{\prime}$-trimethylspiro[2H-1-benzopyron-2,2'- 
indoline]-6-sulfonic acid in the anionic $0.2 \mathrm{M}$ AOT/0.6 $\mathrm{M} \mathrm{H}$ O/hexane reversed micelles were retarded by about 20 times compared with those in MeOH in which microscopic polarity was comparable to that in the interior core of the reversed micelles adopted [8]. This rate deceleration has been explained in terms of the ability of an increase in the microviscosity to restrict the mobility of the substrate in the reversed micellar core.

obviously, the marked acceleration in the present system is unusual and could not be explicable by any of those effects previously advanced. We do not know the exact reason for this previously unprecedented acceleration effect of the micelles at the present moment. It is quite tempting, however, to suppose that the charge of the DDAC head plays an important role. The reverse photochromism suggests that $\mathrm{MC}-1$ is stable relative to SP-1 in polar solvents. This is partly due to the stabilization of MC-1 as a result of the interaction between the positive charge on pyridinium nitrogen and negative charge developed on phenolic oxygen upon heterolytic cleavage of $\mathrm{C}-\mathrm{O}$ bond in SP-1. The max of MC-1 implies that it is located near the zwitterionic heads of DDAC molecules. Presumably, a mutual repulsion between the positively charged nitrogens of DDAC and MC-1 would be significant under these circumstances but should be released by the interaction within MC-1 as advanced above. Additional evidence to support the idea that the surfactant head charge plays an important role was obtained by the findings that SP-1 showed "normal" photochromism in the $\mathrm{AOT} / \mathrm{H}_{2} \mathrm{O} /$ hexane reversed micelles [10].

[1] E. Fischer, Y. Hirshberg, J. Chem. Soc., (1952), 4522.

[2] G. H. Brown, Ed., "Photochromism", Wiley-Interscience, New York (1971), p33-431.

[3] K. Horie, I. Mita, Kobunshi, 34 (1985), 448; G. Smetz, Adv. Polym. Sci., $50(1983), 17$.

[4] D. A. Holden, H. Ringsdorf, V. Deblawwe, J. Phys. Chem., 88 (1984), 716.

[5] B. Nadolski, P. Uznanski, M. Kryszewski, Macromol. Chem., Rapid Commun., $\underline{5}$ (1984), 327; T. Seki, K. Ichimura, J. Chem. Soc., Chem. Commun., (1987); T. Seki, K. Ichimura, J. Photopolym. Sci. Tech., 1 (1988), 254.

[6] E. Ando, J. Miyazaki, K. Morimoto, H. Nakahara, K. Fukada, Thin Solid Films, 13 (1985), 21.

[7] V. Ramesh, M. M. Labes, J. Am. Chem. Soc.,109 (1987), 3228.

[8] J. Sunamoto, K. Iwamoto, M. Akutagawa, M. Nagase, H. Kondo, J. Am. Chem. Soc., 104 (1982), 4904.

[9] I. Shimazu, H. Kokado, E. Inoue, Kogyo Kagaku Zasshi, 72 (1962), 171 ; I. Shimazu, H. Kokado, E. Inoue, Bull. Chem. Soc. Jpn., 42 (1969), 1730.

[10] H. Tomioka, F. Inagaki, unpublished observation. 